\title{
Infantile fever-triggered acute liver failure caused by novel neuroblastoma amplified sequence mutations: a case report
}

\author{
Weiran Li ${ }^{1,2}$, Yu Zhu ${ }^{1,2}$, Qin Guo ${ }^{1,2^{*}}$ and Chaomin Wan ${ }^{1,2^{*}}$
}

\begin{abstract}
Background: Infantile liver failure syndrome-2 (ILFS2) is caused by neuroblastoma amplified sequence (NBAS) mutation. The disease is characterized by recurrent episodes of acute liver failure (ALF) or by liver crisis triggered by recurrent episodes of fever and complete recovery.

Case presentation: Here, we describe the case of a Chinese girl with typical clinical manifestation of ILFS2 without exhibition of extrahepatic involvement. The patient harbored novel compound heterozygous mutations in the NBAS region (c.3386C > T (p.Ser1129Phe), c.1A > C (p.Met1Leu) and c.875G > A (p.Gly292Glu)), mutations which have not been previously reported. After administration of antipyretics and intravenous glucose and electrolyte administration, the patient recovered fully.

Conclusion: Through the present study, we recommend that ILFS2 should be taken into consideration during the differential diagnosis of children with recurrent, fever-triggered ALF. While the definitive diagnosis of ILFS2 remains dependent on genetic sequencing and discovery of NBAS, early antipyretic treatment is recommended to prevent liver crisis.
\end{abstract}

Keywords: NBAS, Acute liver failure, Infantile liver failure syndrome type 2, Whole exome sequencing

\section{Background}

Acute liver failure (ALF) is a rare condition in children, however, it is associated with a higher risk of mortality. Although the etiology of ALF in about $50 \%$ of cases remains unexplained [1], hereditary metabolic disorders comprise of a large number of ALF in pediatric populations $[2,3]$. Recently, biallelic mutations in the neuroblastoma amplified sequence (NBAS) were reported as a novel cause of infantile liver failure syndrome-2 (ILFS2). ILFS2 is an autosomal recessive genetic disease characterized by recurrent episodes of ALF or liver crisis triggered by fever. Previously, the mutations within the

\footnotetext{
*Correspondence: joy1122@163.com; wcm0220@126.com

'Department of Paediatrics, West China Second University Hospital, Sichuan University, No 20, 3rd section of Renmin South Road, Chengdu 610041, PR China

Full list of author information is available at the end of the article
}

NBAS were reported to be the cause of short stature, optic atrophy and Pelger-Huët anomaly of granulocytes $(\mathrm{SOPH})$ syndrome in an isolated Russian yakut population [4]. Increasing research has reported that the phenotype spectrum of NBAS mutations ranges from isolated ILFS2 to a multi-systemic disease including short stature, skeletal dysplasia and optic atrophy [5-8]. Early administration of antipyretic and support therapy can effectively ameliorate the course of ILFS2 due to NBAS mutations, improving the prognosis $[8,9]$. Thus, it is important to confirm the diagnosis of ILFS2 at the earliest stage possible. Here, we report a case of isolated ILFS2 caused by novel NBAS mutation in a Chinese girl aged 3 years and 8 months. This report also reviews NBAS-related cases in the medical literature.

(c) The Author(s). 2020 Open Access This article is licensed under a Creative Commons Attribution 4.0 International License, which permits use, sharing, adaptation, distribution and reproduction in any medium or format, as long as you give appropriate credit to the original author(s) and the source, provide a link to the Creative Commons licence, and indicate if changes were made. The images or other third party material in this article are included in the article's Creative Commons licence, unless indicated otherwise in a credit line to the material. If material is not included in the article's Creative Commons licence and your intended use is not permitted by statutory regulation or exceeds the permitted use, you will need to obtain permission directly from the copyright holder. To view a copy of this licence, visit http://creativecommons.org/licenses/by/4.0/. The Creative Commons Public Domain Dedication waiver (http://creativecommons.org/publicdomain/zero/1.0/) applies to the data made available in this article, unless otherwise stated in a credit line to the data. 


\section{Case presentation}

A 3 year and 8 month old Chinese girl born at term to healthy, non-consanguineous parents by normal vaginal delivery had no family history of liver disease. At the age of 2 years and 11 months, the patient presented recurrent fever with cough, vomiting, decreased activity, and lethargy agitated for 3 weeks upon admission to our hospital. She had severe jaundice without hepatomegaly, however the rest of the physical examinations (growth and development, skeletal system, nervous system and motor ability, integument and facial profile) were normal. Laboratory evaluations indicated extreme damage to liver functions and severe coagulopathy (Table 1). Serum creatinine (Cre) and blood urea nitrogen (BUN) were normal. Creatine kinase (CK) and cardiac troponin I (cTnI) were mildly elevated at $149 \mathrm{U} / \mathrm{L}$ (normal range: $30-135$ ) and $0.055 \mu \mathrm{g} / \mathrm{L}$ (normal range: 0 $0.034)$ respectively, suggesting myocardial injury. The white blood cell (WBC) count was significantly increased $\left(15.8^{*} 10^{9} / \mathrm{L}\right.$, normal range:3.6-13) and neutrophils accounted for $81 \%\left(12.77^{*} 10^{9} / \mathrm{L}\right.$, normal range:0.72-4.80). C-reactive protein (CRP) was also elevated $(39 \mathrm{mg} / \mathrm{L}$, normal range:0-8). The patient was diagnosed with ALF and managed with antipyretics, plasmapheresis, hepatoprotectives (e.g., Polyene Phosphatidyl Choline and Ademetionine Butanedisulfonate) and intravenous infusion of glucose and potassium chloride. Following treatment, the liver function of the patient was restored completely.
Eight months later, at the age of 3 years and 7 months, the patient was readmitted during a second episode of liver crisis following an upper respiratory tract infection with fever (up to $39^{\circ} \mathrm{C}$ ) and cough. Physical examinations revealed mild jaundice with an enlarged liver (palpable $2.5 \mathrm{~cm}$ below the costal margin). Laboratory data indicated a recurrence of significant damage of liver function and severe coagulopathy (Table 1). The value of CK, cTnI, Cre and BUN were normal during this episode and the trends of WBC and CRP were similar to those of the first episode. Again, after treatment including antipyretics, antibiotics, hepatoprotectives and intravenous glucose and potassium chloride, the patient fully recovered.

At the age of 3 years and 8 months, the patient was once again re-admitted with ALF after a $12 \mathrm{~h}$ persistence of fever (maximum temperature: $39.3^{\circ} \mathrm{C}$ ) and vomiting. Physical examination revealed hepatomegaly (palpable $1.5 \mathrm{~cm}$ below the costal margin), a few bleeding spots in her chest, and herpes in her right soft palate along with an ulcer $(3 * 3 \mathrm{~mm})$ in the right isthmus of fauces. No jaundice was observed. The clinical features and elevation of liver enzymes with coagulopathy were similar to previous episodes (Table 1). Coxsackievirus A16 nucleic acid detection was positive. Other laboratory results presented similar changes to those observed during the second episode. Complete recovery of the patient was

Table 1 Clinical features and laboratory results of the presented patient

\begin{tabular}{|c|c|c|c|}
\hline \multirow{2}{*}{$\begin{array}{l}\text { Clinic features \& } \\
\text { laboratory results }\end{array}$} & \multicolumn{3}{|l|}{ Result } \\
\hline & Age of 2 year and 11 months & Age of 3 year and 7 months & Age of 3 years and 8 months \\
\hline Symptom & Recurrent fever & Recurrent fever with cough & Fever with vomit \\
\hline Body sign & Severe Jaundice & Mild Jaundice, Hepatomegaly & $\begin{array}{l}\text { Hepatomegaly, A few bleeding spots in } \\
\text { her chest, Herpes in right soft palate, An } \\
\text { ulcer }\left(3^{*} 3 \mathrm{~mm}\right) \text { in right isthmus of fauces }\end{array}$ \\
\hline Max temperature $\left({ }^{\circ} \mathrm{C}\right)$ & $>38.5$ & 39.0 & 39.3 \\
\hline ALT(U/L) (Normal range:9-52) & 9787 & 6378 & 4096 \\
\hline AST (U/L) (Normal range:14-36) & 12,489 & 9924 & 4857 \\
\hline TBIL (umol/L) (Normal range:3-22) & 44.3 & 22.4 & 28.4 \\
\hline DBIL (umol/L) (Normal range:0-5) & 24.10 & 7.30 & 16.9 \\
\hline IBIL (umol/L) (Normal range:0-19) & 20.20 & 15.10 & 11.50 \\
\hline Albumin (g/L) (Normal range:35-50) & 41.9 & 44.1 & 36.8 \\
\hline Y-GT (U/L) (Normal range:12-43) & 26 & 48 & 42 \\
\hline LDH (U/L) (Normal range:313-618) & 21,786 & 22,854 & 6492 \\
\hline PT (s) (Normal range:8.7-14.7) & 63.9 & 15.6 & 25.9 \\
\hline INR (Normal range:0.8-1.5) & 5.50 & 1.48 & 2.47 \\
\hline APTT (s) (Normal range:17.5-37.5) & 45.0 & 25.1 & 25.5 \\
\hline FIB (mg/dL) (Normal range:200-400) & 221 & 327 & 310 \\
\hline$\Pi$ Tा (s) (Normal range:14-21) & 24.3 & 20.2 & 19.1 \\
\hline
\end{tabular}

NA Not available, ALT Alanine transaminase, AST Aspartate aminotransferase, TBIL Total bilirubin, DBIL Direct Bilirubin, IBIL Indirect Bilirubin, $\gamma$-GT $\gamma$-glutamyl transpeptidase, $L D H$ Lactate dehydrogenase, PT Prothrombin time, INR International normalized ratio, APTT Activated partial thromboplastin time, FIB Fibrinogen $\pi$ Thrombin time 
achieved with a similar treatment plan to the previous admission.

During the three admissions, metabolic evaluations indicated hyperammonemia (40.0 umol/L; Normal range: 9-30) and hypoglycemia (3.77 mmol/L; Normal range: 4.1-5.9). Lactate, ceruloplasmin, alpha-fetoprotein and pyruvate values were all normal. However, there was a remarkable elevation of $\beta$-hydroxybutyrate $(1.81 \mathrm{mmol} /$ L; Normal range:0-0.27). Serum amino acid test presented elevations of pipecolic acid $(551.318 \mu \mathrm{M}$; normal range: 100-438) and the ratio of leucine to alanine (1.359; normal range:0.06-1.00). The values of acyl carnitines were normal in the plasma. Metabolic biomarkers in the urine showed that the value of ketone bodies, methionine, adenine and adenosine were all increased. The immunological indicators including complement C3 and C4 levels, serum immunoglobulin levels and the count of $\mathrm{T}$ lymphocyte, B lymphocyte, natural killer cells, and helper $\mathrm{T}$ cells were all unremarkable. Further, a panel of serology tests for infectious agents including HIV virus, treponema pallidum, hepatitis B virus, hepatitis $C$ virus, Epstein-Barr virus, toxoplasma, rubella virus and herpes simplex virus were all negative. No Pelger-Huët anomaly of granulocytes was found in either of multiple blood smears. A percutaneous liver biopsy was undertaken at the third admission. This showed nonspecific, mild acute hepatitis with hydropic degeneration of hepatic cells and small foci of lobular necrosis. There were a small number of lymphocytes, monocytes and plasma cells infiltrating in the portal area. Foot and Masson stain showed fibroplasia and the enlargement of some portal areas. Berlin blue, rhodanine, rubeanic acid, Periodic Acid-Schiff and diastase peniodic acid-Sehiff stain were normal. In order to identify the cause for recurrent ALF, whole exome sequencing was performed in the patient and her parents. Three rare heterozygous mutations in the NBAS gene were detected: c.3386C $>T$ (p.Ser1129Phe), c.1A $>C$ (p.Met1Leu) and c.875G >A (p.Gly292Glu), the latter of which have not been previously reported. Parental genotyping showed that the $c .3386 C>T$ (p.Ser1129Phe) and c.875G > A (p.Gly292Glu) mutation occurred in a heterozygous state in the mother and the $c .1 A>C$ (p.Met1Leu) mutation in a heterozygous state in the father, presenting compound heterozygosity of the NBAS variants in the girl. According to the guidelines of The American College of Medical Genetics Genomics and the Association for Molecular Pathology (ACMG), the pathogenicity of the $c .1 A>C$ (p.Met1Leu) mutation was greater than $90 \%$. The pathogenicity of the other two mutations, however, was uncertain. Prediction of protein biological function was carried out with software including SIFT, MutationTaster and GERP++, which indicated that two of the mutations $(c .3386 C>T$
(p.Ser1129Phe) and c.1A $>C$ (p.Met1Leu)) were pathogenic while the $c .875 G>A$ (p.Gly292Glu) mutation was nonpathogenic. Specifically, for the mutation of c.3386C > $\mathrm{T}$ (p.Ser1129Phe), the score and prediction of SIFT, MutationTaster and GERP++ were (0.001, damaging), (1, disease causing) and (5.74, conserved) respectively. Regarding the mutation of c.1A > C (p.Met1Leu), the score and prediction of SIFT, MutationTaster and GERP++ were ( 0 , damaging), (1, disease causeing) and (5.2, conserved) respectively. For the mutation of c.875G $>$ A (p.Gly292Glu), these values were (1, tolerated), (1, polymorphism) and ( -3.5 , nonconseved) respectively.

\section{Discussion and conclusions}

ILFS2 is a rare condition characterized by episodic liver failure or crisis triggered by recurrent fever. Liver function can be fully recovered after conservative treatment. It was first reported by Haack et al. that ILFS2 is caused by biallelic mutations in the NBAS gene [10]. NBAS mutations have also been identified in SOPH syndrome patients without liver failure [4]. An increasing number of studies have indicated that diseases based on NBAS mutations have a broad phenotypic spectrum, ranging from isolated recurrent ILFS2 to a multi-systemic disease manifesting as short stature, skeletal dysplasia, dysmorphism and optic atrophy with or without liver failure [4-9, 11-18].

A literature search found 56 reported cases of NBASassociated disease (Table 2). The median onset age of these patients was 0.8 years (interquartile range:0.1-6.7 years) however only 47 patients were considered due to missing data of onset age. The ratio of female to male patients was 17 to 13 , however, only 30 patients were analyzed due to incomplete data of sex. The clinical manifestations of the hereditary disease were characterized by two aspects including intrahepatic and extrahepatic symptoms. On the one hand, the phenotype of liver illness is usually triggered by febrile illness and manifested as recurrent ALF or liver crisis, where complete recovery is typical during the interval of episodes. It usually begins with rapid increased value of alanine transaminase and aspartate transaminase, indicating functional liver damage. Mild to severe coagulopathy, jaundice and hepatomegaly are manifested in most cases. Secondary metabolism disorders, such as elevation of lactate and serum ketone bodies, hypoglycemia, and hyperammonemia are sometimes observed in these patients [7, 9]. Moreover, some patients present hepatic encephalopathy or death due to untimely treatment. On the other hand, the main extrahepatic manifestation of NBAS mutations are short stature, skeletal dysplasia, optic atrophy, Pelger-Huët anomaly of granulocytes or immunological abnormalities [7, 13, 17]. Previous researchers have reported that among the 56 reported patients with NBAS-associated disease, 43 patients $(76.8 \%)$ 


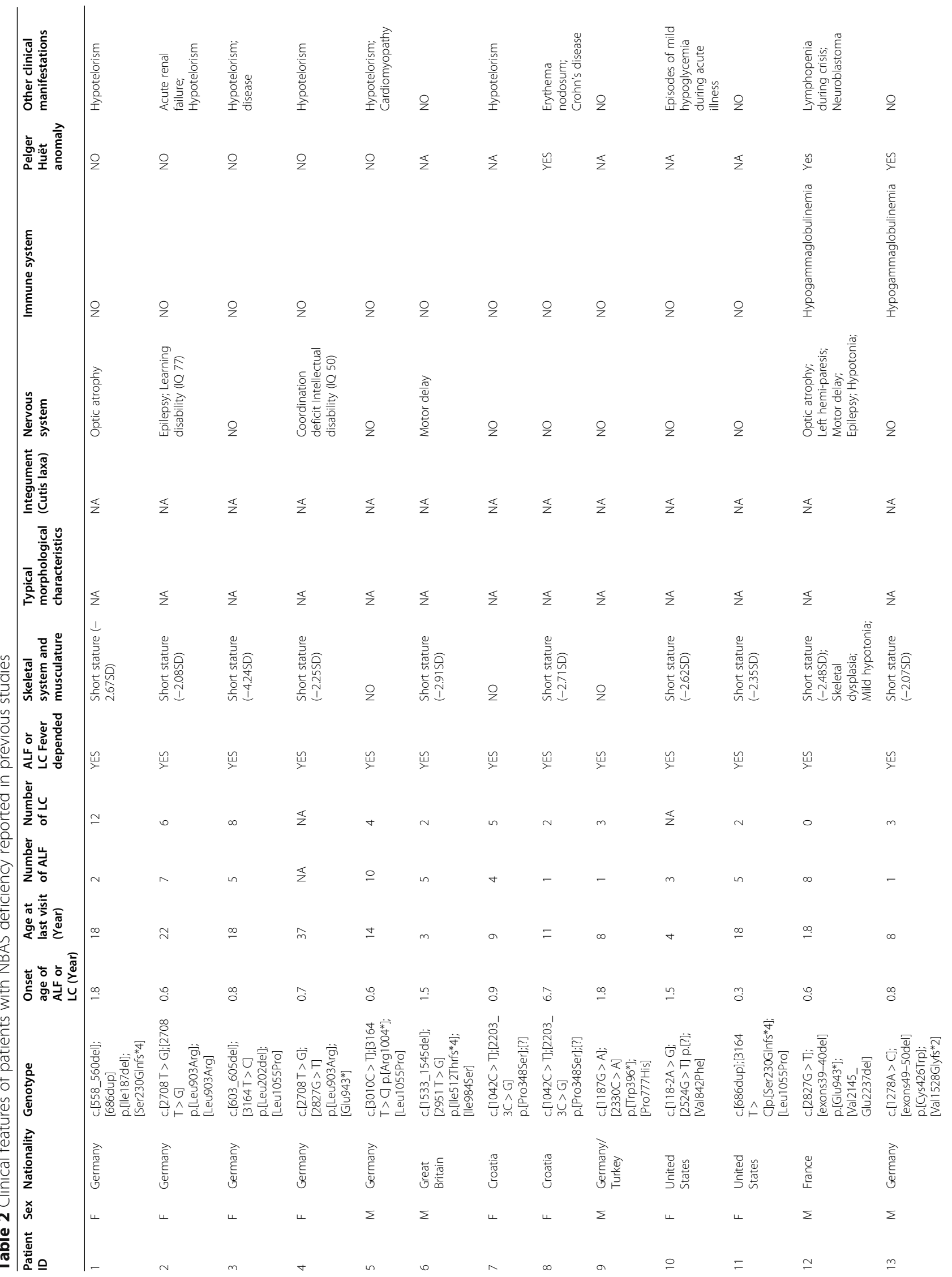




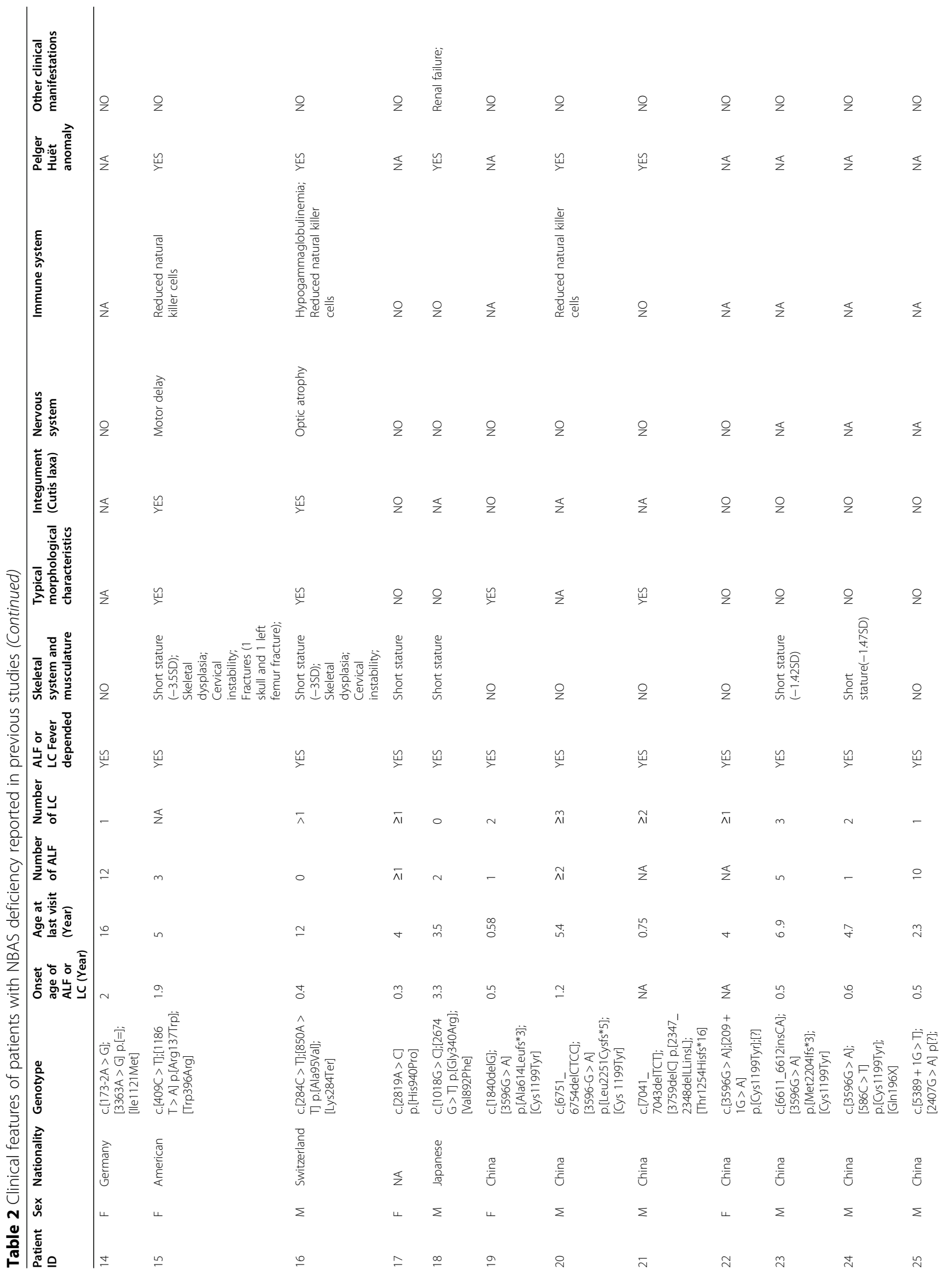




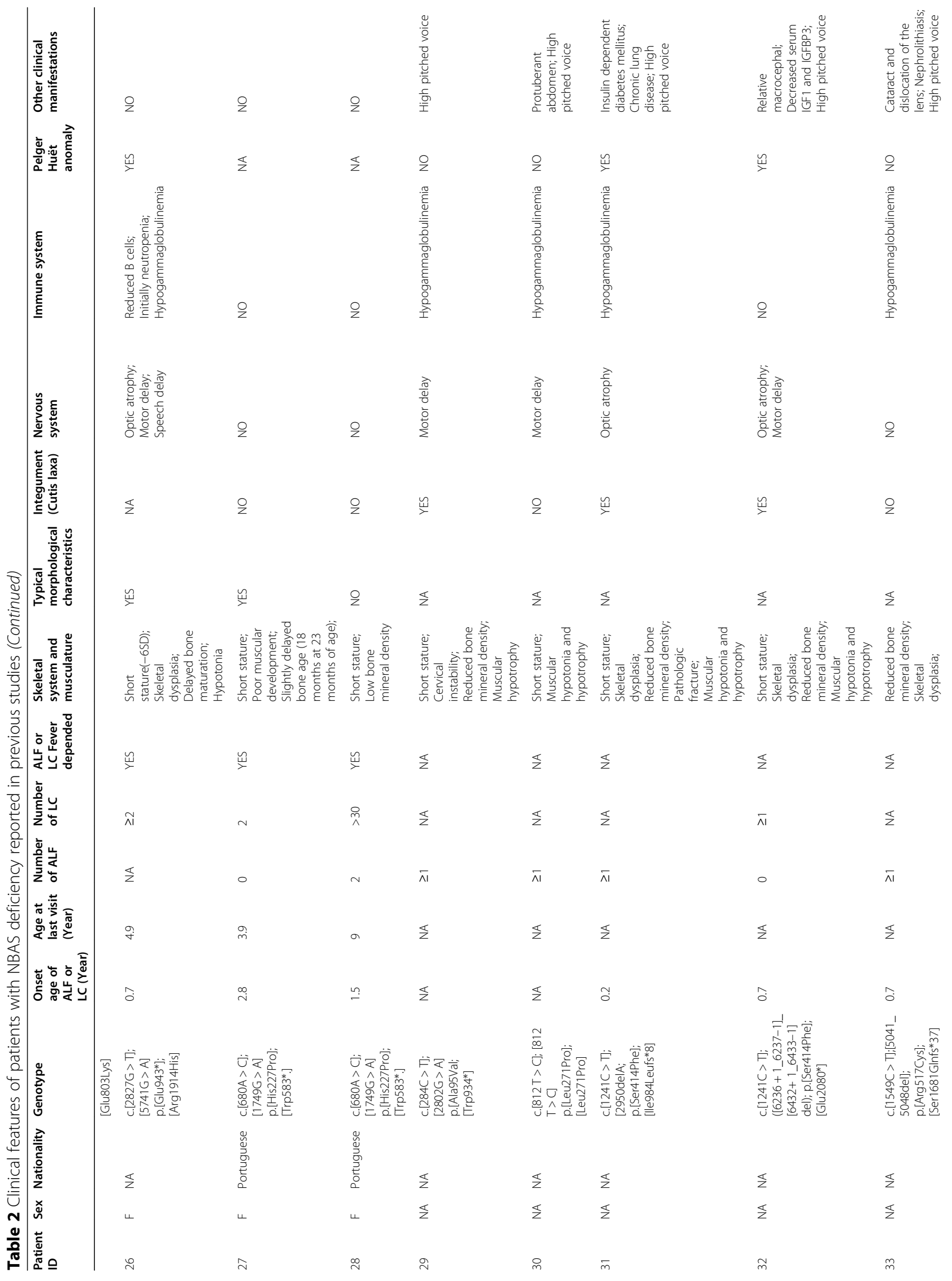




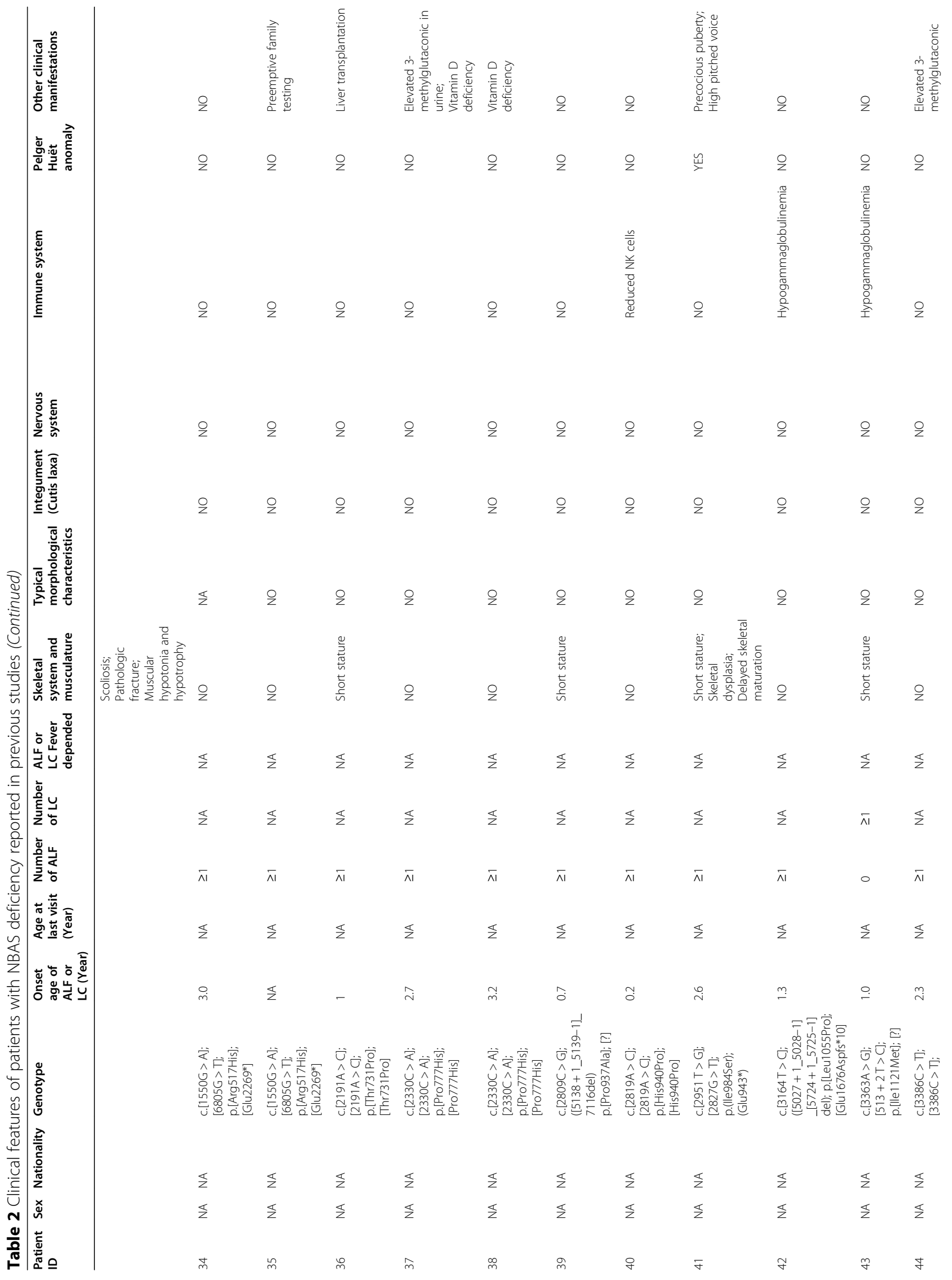




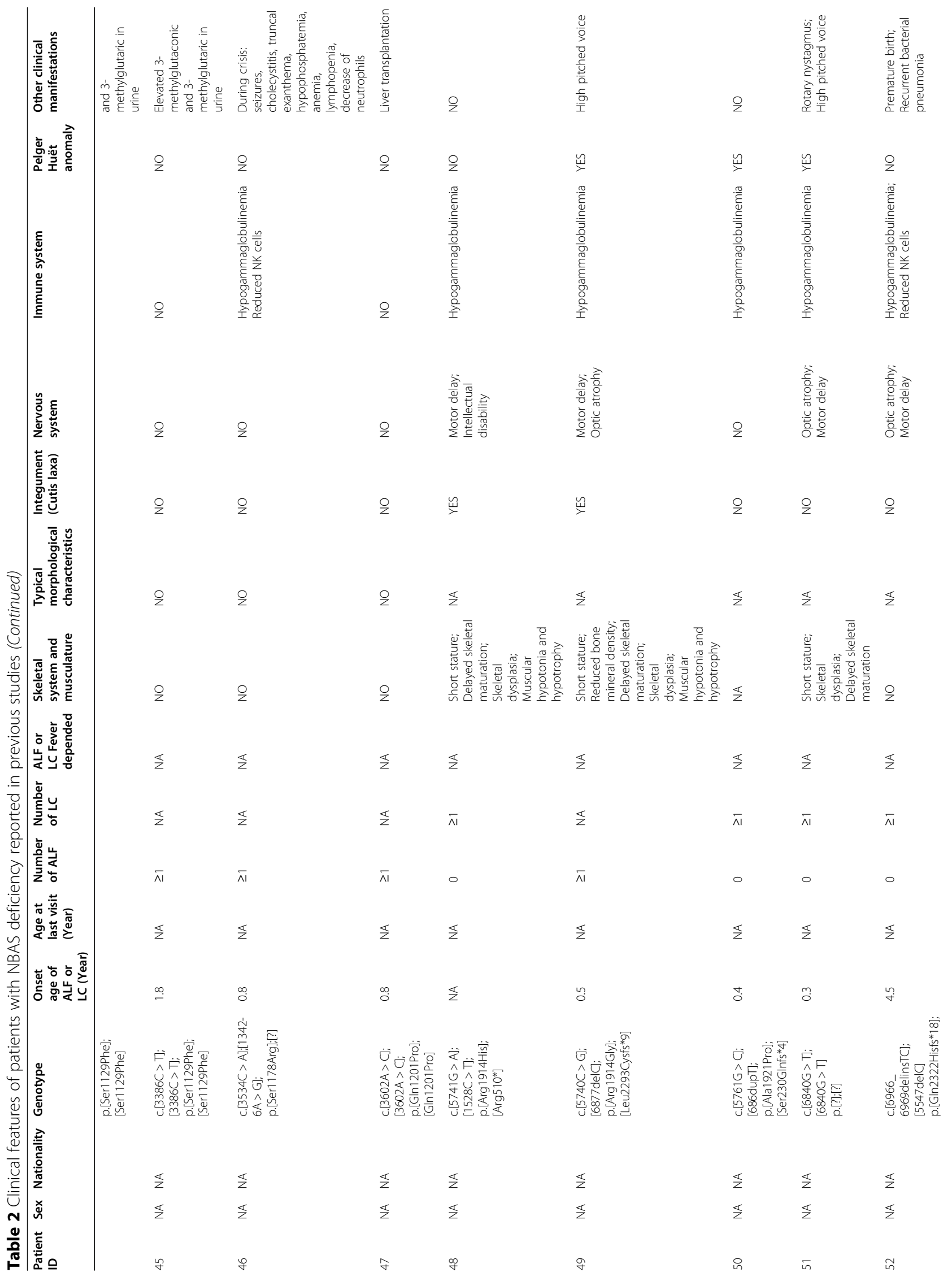




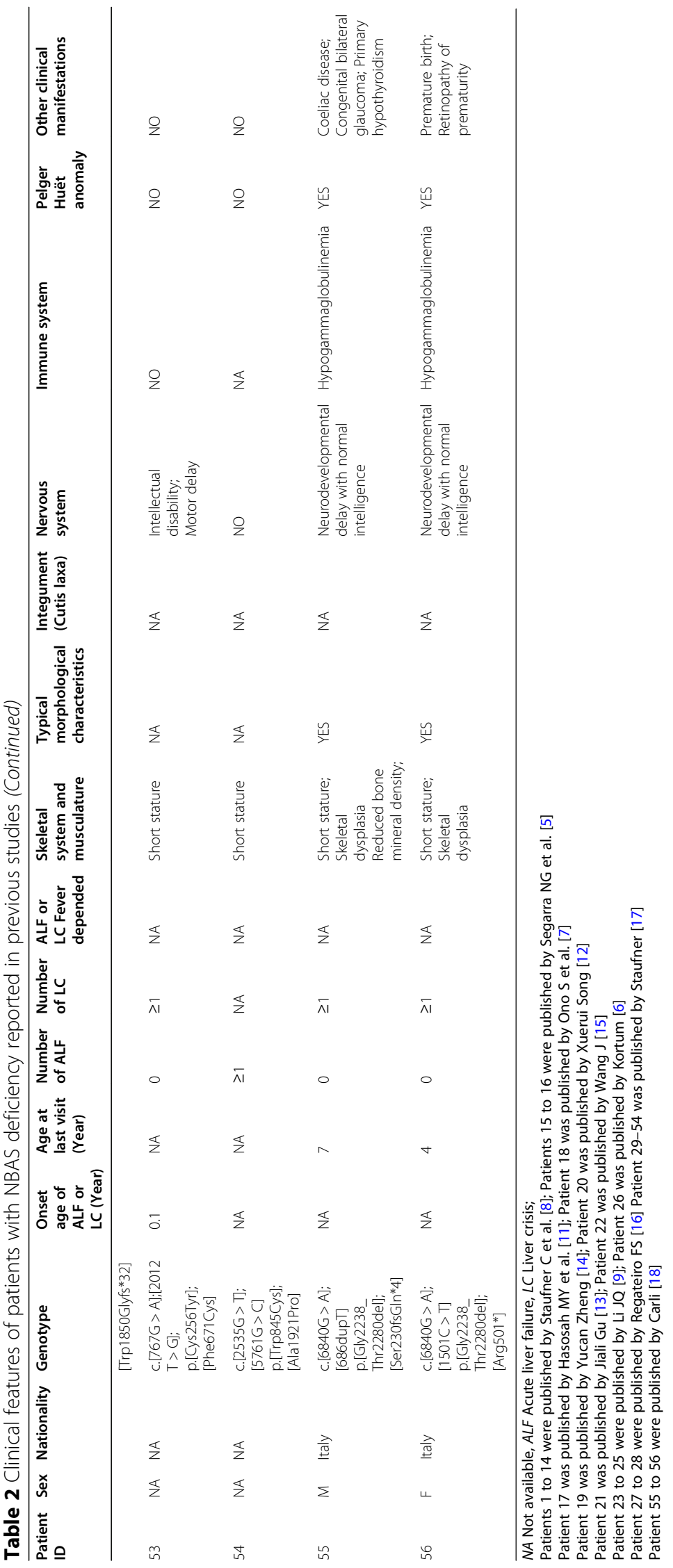


presented ILFS2 with multi-systemic manifestations, where short stature was the most common extrahepatic manifestations (34/43, 79.1\%). Only 13 cases $(23.2 \%)$ presented isolated ILFS2 (Table 2). The present case reported a 3 years and 8 months old girl with ILFS2 who experienced the first episode at 2 years and 11 months of age and it presented herein details isolated ILFS2 with coagulopathy, jaundice and hepatomegaly, where no extrahepatic abnormalities were observed. We speculated that the clinical manifestations may be associated with the different gene mutation profile of this patient.

Although the clinical manifestation of ILFS2 in this case report was typical, the definitive diagnosis of this disease depended on whole exome sequencing as it was important to rule out ALF caused by drugs, infection or simultaneous autoimmune abnormality. Many mutation sites in the NBAS gene have been reported $[5,7,8]$. Through NBAS sequencing, it was determined that three heterozygous mutations occurred in the patient under discussion. Specifically, (c.3386C $>T$ (p.Ser1129Phe), c. $1 A>C$ (p.Met1Leu) and c.875G > A (p.Gly292Glu)). Regarding the $c .3386 C>T$ (p.Ser1129Phe) mutation, Staufner et al. have reported that two patients who harbored this mutation similarly presented ALF without other extrahepatic manifestations [17]. The onset age of those two patients were 2.3 and 1.8 years respectively, close to the age of onset for our patient ( 2.9 years). Staufner et al. indicated that the $c .3386 C>T$ (p.Ser1129Phe) mutation affected the region coding for the Sec39 domain of the NBAS gene, which is necessary for tethering at the endoplasmic reticulum (ER) in the syntaxin18 [17]. The c. $1 A>C$ (p.Met1Leu) mutation is a likely pathogenic mutation (90\% pathogenicity) according to the guidelines of the ACMG. Further, the software for the prediction of protein biological function have also indicated that this mutation is likely pathogenic. Thus, we speculated that the mutations including $c .3386 C>T$ (p.Ser1129Phe) and c.1A>C (p.Met1Leu) are associated with the IFS2 while the $c .875 G>A$ (p.Gly292Glu) mutation was likely nonpathogenic.

To date, the molecular pathogenesis of ALF in NBAS deficiency has remained unclear. The biological role of NBAS is two-fold. As a subunit of the syntaxin 18 complex which is thermally susceptible, it is associated with Golgi-to-ER retrograde transport [19]. On the other hand, NBAS plays an important role in nonsensemediated mRNA decay control [20]. The dysfunction of the syntaxin 18 complex caused by NBAS deficiency may alter Golgi-to-ER retrograde vesicular trafficking, which in turn may lead to liver dysfunction and eventually, failure $[8,10]$.

Complete recovery of liver function in patients with IFLS2 can be achieved through comprehensive treatment. Therapeutic experience shows that early antipyretic therapy and treatment of the primary diseases that trigger fever is effective and able to prevent life-threatening ALF. Additionally, support treatments including intravenous infusion of lipid and glucose to maintain the internal environment stable and energy replete expedite recovery $[8,11]$. Generally, liver transplantation is not considered unless intensive conservative treatment is ineffective. The patient in our study received antipyretics in addition to other conservative strategies including plasmapheresis (only in first episode), hepatoprotectives and intravenous glucose and electrolyte infusion. These treatments led to a remarkable recovery.

The present case detailed the course of a Chinese girl with ILFS2 presenting typical clinical characteristics of the disease-without the involvement of extrahepatic systems. The patient was found to harbor novel compound heterozygous mutations in the NBAS $(c .3386 C>T$ (p.Ser1129Phe), c.1A $>C$ (p.Met1Leu) and c.875G $>A$ (p.Gly292Glu)), two mutations of which have not been previously reported. Here we suggest that ILFS2 should be considered as a part of the differential diagnoses of children presenting with recurrent ALF triggered by fever. However, the definitive diagnoses of ILFS2 continues to depend on sequencing results of NBAS as well as the elimination of other potential causes of ALF including drug reactions, infections and autoimmune hepatitis. Early and effective antipyretic and support treatments such as intravenous lipid and glucose infusion are also recommended as these can prevent further liver crisis and lead to faster recovery.

\section{Abbreviations \\ ALF: Acute liver failure; NBAS: Neuroblastoma amplified sequence; ILFS2: Infantile liver failure syndrome-2; SOPH: Optic never atrophy and Pelger-Huët anomaly of granulocytes; Cre: Creatinine; CK: Creatine kinase CTnl: Cardiac troponin I; WBC: White blood cell; CRP: C-reactive protein; ACMG: The American College of Medical Genetics Genomics and the Association for Molecular Pathology; ER: Endoplasmic reticulum}

\section{Acknowledgements}

Not applicable.

Authors' contributions

$W L$ and $Y Z$ collected the clinical data and carried out the initial analyses, drafted the initial manuscript. QG and CW reviewed and revised the manuscript. The authors have read and approved the final manuscript.

\section{Authors' information}

All authors belong to Department of Pediatrics, West China Second University Hospital, Sichuan University, No 20, 3rd section of Renmin South Road, Chengdu 610041, People's Republic of China. Key Laboratory of Birth Defects and Related Diseases of Women and Children (Sichuan University), Ministry of Education, Chengdu, People's Republic of China.

\section{Funding}

This project was supported by a grant from Pediatric Clinical Research Center Foundation of Sichuan Province, China (No.2017-46-4), National Science and Technology Major Project of China (No.2018ZX10103-001) the Fundamental Research Funds for Central Universities (No.2012017yjsy196) and Research development project of Sichuan Provincial Science and Technology

Department (No.2018SZ0130). The views expressed are those of the authors and not necessarily those of funders. The funders were not directly involved in the collection, analysis, and interpretation of data or in writing the 
manuscript. Prior to the grant being awarded, the funding body provided feedback on the study design.

\section{Availability of data and materials}

Not applicable.

\section{Ethics approval and consent to participate}

This study protocol was approved by the Ethical Committee of West China Second University Hospital, Sichuan University. Written informed consent was obtained from guardians of this patient prior to study enrollment.

\section{Consent for publication}

Written informed consent was obtained from the patient's parents for the publication of this case report and all information contained in it.

\section{Competing interests}

The authors declare that they have no competing interests.

\section{Author details}

'Department of Paediatrics, West China Second University Hospital, Sichuan University, No 20, 3rd section of Renmin South Road, Chengdu 610041, PR China. ${ }^{2}$ Key Laboratory of Birth Defects and Related Diseases of Women and Children (Sichuan University), Ministry of Education, Chengdu, PR China.

Received: 4 December 2019 Accepted: 11 September 2020

Published online: 21 September 2020

\section{References}

1. Narkewicz MR, Dell Olio D, Karpen SJ, Murray KF, Schwarz K, Yazigi N, et al. Pattern of diagnostic evaluation for the causes of pediatric acute liver failure: an opportunity for quality improvement. J Pediatr. 2009;155(6):801-6 e801.

2. Dhawan A. Etiology and prognosis of acute liver failure in children. Liver Transpl. 2008;14(10):S80-4.

3. Vilarinho S, Choi M, Jain D, Malhotra A, Kulkarni S, Pashankar D, et al. Individual exome analysis in diagnosis and management of paediatric liver failure of indeterminate aetiology. J Hepatol. 2014:61(5):1056-63.

4. Maksimova N, Hara K, Nikolaeva I, Chun-Feng T, Usui T, Takagi M, et al. Neuroblastoma amplified sequence gene is associated with a novel short stature syndrome characterised by optic nerve atrophy and Pelger-Huet anomaly. J Med Genet. 2010;47(8):538-48.

5. Segarra NG, Ballhausen D, Crawford H, Perreau M, Campos-Xavier B, van Spaendonck-Zwarts K, et al. NBAS mutations cause a multisystem disorder involving bone, connective tissue, liver, immune system, and retina. Am J Med Genet A. 2015;167A(12):2902-12.

6. Kortum F, Marquardt I, Alawi M, Korenke GC, Spranger S, Meinecke P, et al. Acute liver failure meets SOPH syndrome: a case report on an intermediate phenotype. Pediatrics. 2017;139(1):e20160550.

7. Ono S, Matsuda J, Watanabe E, Akaike H, Teranishi H, Miyata I, et al. Novel neuroblastoma amplified sequence (NBAS) mutations in a Japanese boy with fever-triggered recurrent acute liver failure. Hum Genome Var. 2019;6:2.

8. Staufner C, Haack TB, Kopke MG, Straub BK, Kolker S, Thiel C, et al. Recurrent acute liver failure due to NBAS deficiency: phenotypic spectrum, disease mechanisms, and therapeutic concepts. J Inherit Metab Dis. 2016;39(1):3-16.

9. Li JQ, Qiu YL, Gong JY, Dou LM, Lu Y, Knisely AS, et al. Novel NBAS mutations and fever-related recurrent acute liver failure in Chinese children: a retrospective study. BMC Gastroenterol. 2017;17(1):77.

10. Haack TB, Staufner C, Kopke MG, Straub BK, Kolker S, Thiel C, et al. Biallelic mutations in NBAS cause recurrent acute liver failure with onset in infancy. Am J Hum Genet. 2015;97(1):163-9.

11. Hasosah MY, Iskandarani Al, Shawli Al, Alsahafi AF, Sukkar GA, Qurashi MA. Neuroblastoma amplified sequence gene mutation: a rare cause of recurrent liver failure in children. Saudi I Gastroenterol. 2017;23(3):206-8.

12. Xuerui Song ZC, Cheng X, Zhou F, Zhou L, Zhao X, An Y. Clinical and immunological characteristics of a case with ILFS2. Immunological J. 2019; 35(6):512-8.

13. Jiali Gu WW, Li LI, Zheng Y, Mao X. A novel compound heterozygous mutation in NBAS gene causes SOPH syndrome and liver function damage. Chin J Pediatr. 2019:57(6):487-9.

14. Yucan Zheng $\mathrm{J}$, Guo $\mathrm{H}$. One case of infantile liver failure syndrome-2. Chin J Pediatr. 2018;2018(56):876-7.
15. Wang J, Pu ZJ, Lu ZH. Targeted next-generation sequencing reveals two novel mutations of NBAS in a patient with infantile liver failure syndrome-2. Mol Med Rep. 2018;17(2):2245-50.

16. Regateiro FS, Belkaya S, Neves N, Ferreira S, Silvestre P, Lemos S, et al. Recurrent elevated liver transaminases and acute liver failure in two siblings with novel bi-allelic mutations of NBAS. Eur J Med Genet. 2017;60(8):426-32.

17. Staufner C, Peters B, Wagner M, Alameer S, Baric I, Broue $P$, et al. Defining clinical subgroups and genotype-phenotype correlations in NBAS-associated disease across 110 patients. Genet Med. 2020;22(3):610-21.

18. Carli D, Giorgio E, Pantaleoni F, Bruselles A, Barresi S, Riberi E, et al. NBAS pathogenic variants: defining the associated clinical and facial phenotype and genotype-phenotype correlations. Hum Mutat. 2019;40(6):721-8.

19. Aoki T, Ichimura S, Itoh A, Kuramoto M, Shinkawa T, Isobe T, et al. Identification of the neuroblastoma-amplified gene product as a component of the Syntaxin 18 complex implicated in Golgi-to-endoplasmic reticulum retrograde transport. Mol Biol Cell. 2009;20(11):2639-49.

20. Longman D, Hug N, Keith M, Anastasaki C, Patton EE, Grimes G, et al. DHX34 and NBAS form part of an autoregulatory NMD circuit that regulates endogenous RNA targets in human cells, zebrafish and Caenorhabditis elegans. Nucleic Acids Res. 2013;41(17):8319-31.

\section{Publisher's Note}

Springer Nature remains neutral with regard to jurisdictional claims in published maps and institutional affiliations.
Ready to submit your research? Choose BMC and benefit from:

- fast, convenient online submission

- thorough peer review by experienced researchers in your field

- rapid publication on acceptance

- support for research data, including large and complex data types

- gold Open Access which fosters wider collaboration and increased citations

- maximum visibility for your research: over $100 \mathrm{M}$ website views per year

At $\mathrm{BMC}$, research is always in progress.

Learn more biomedcentral.com/submissions 